\title{
The Preparation and Characterization of Alumina Membranes with Ultrafine Pores
}

\section{The Formation of Supported Membranes}

\author{
A. F. M. LEENAARS ${ }^{1}$ AND A. J. BURGGRAAF \\ Department of Chemical Engineering, Laboratory for Inorganic Chemistry and Materials Science, \\ Twente University of Technology, P.O. Box 217, 7500 AE Enschede, The Netherlands
}

Received January 31, 1984; accepted July 2, 1984

\begin{abstract}
Supported $\gamma-\mathrm{Al}_{2} \mathrm{O}_{3}$ membranes are prepared by a dipping procedure. According to this method, a capillary pressure drop is created by bringing a microporous ceramic support into contact with a boehmite $(\gamma-\mathrm{AlOOH})$ sol. This pressure drop forces the dispersion medium of the sol to flow into the dry part of the support. The sol particles are concentrated at the entrance of the pores and a gel is formed. This gel can be dried and calcined to form a crack-free alumina membrane with pores measuring only a few nanometers, if the membrane thickness after calcination is about $5 \mu \mathrm{m}$ or less. The gel formation process can be quantitatively well described with the slibcasting model. The observations that the membrane thickness increases linearly with the square root of the dipping time and that the casting rate increases if the sol concentration increases, the pore size of the support decreases or the gelling concentration decreases, are all in accordance with this slibcasting model. (C) 1985 Academic Press, Inc.
\end{abstract}

\section{INTRODUCTION}

A general scheme which is used for the preparation of alumina membranes was presented in part 1 of this series of papers (1). According to this scheme thin alumina films are prepared by a process in which a boehmite $(\gamma-\mathrm{AlOOH})$ sol is successively gelled, dried, and calcined. The microstructures of the gel and the membrane were also discussed. It appeared that the alumina membranes we obtained have pores measuring a few nanometers and a very narrow pore size distribution. An extensive literature evaluation has shown that this type of material is suitable for gas and liquid separation purposes $(2,3)$. The results of separation experiments in liquid media will be presented in another part of this series of publications.

The results of the microstructural investigations presented previously (1), were limited

\footnotetext{
${ }^{1}$ To whom correspondence should be addressed.
}

to nonsupported membranes. We have shown that the microstructure of supported membranes corresponds with that of nonsupported membranes. The synthesis of supported membranes itself was not presented. In this paper the process by which a thin film can be formed on a porous support will be reported and analyzed in detail.

\section{MATERIALS AND METHODS}

Boehmite sols were prepared (1) and subsequently concentrated by boiling, or diluted with distilled water, to obtain suitable sol concentrations. The aluminum content of the sols was determined by $\mathrm{X}$-ray fluorescence and the weight concentrations obtained were converted into volume concentrations using $3 \mathrm{~g} \mathrm{~cm}^{-3}$ for the density of the solid boehmite crystals (4). Unless stated otherwise, the sol has a concentration of $1.22 \pm 0.01 \mathrm{~mole} /$ liter and contains 0.07 mole $\mathrm{HNO}_{3}$ per mole boehmite. 
The properties of the material on which the alumina membrane is formed, i.e., the support, are very important, especially the pore size distribution (cf. Section 3.1). Three types of support materials were used, all being flat circular $\alpha-\mathrm{Al}_{2} \mathrm{O}_{3}$ plates with a crosssection of $3.9 \mathrm{~cm}$ and a thickness of 0.20 $0.22 \mathrm{~cm}$. Type 1 was provided by Philips Elcoma, type 2 was prepared at our laboratory as given below, and type 3 (which also contained $\mathrm{SiO}_{2}$ ) was obtained commercially from the "Staatliche Porzellan Manufaktur," Berlin, West Germany (type P80). The pore size distributions of these support materials were determined with a mercury porosimeter (Carlo Erba, 200 series) and the results are given in Fig. 1. The type 2 supports were prepared from acid stabilized $\alpha-\mathrm{Al}_{2} \mathrm{O}_{3}$ suspensions as follows. Water was added to a mixture of $200 \mathrm{~g} \alpha-\mathrm{Al}_{2} \mathrm{O}_{3}$ (Merck, 1095) and 0.03 mole $\mathrm{HNO}_{3}$ per mole $\alpha-\mathrm{Al}_{2} \mathrm{O}_{3}$, so that a total amount of $200 \mathrm{~cm}^{3}$ liquid was obtained. This mixture was milled with $2 \mathrm{~kg} \alpha$ $\mathrm{Al}_{2} \mathrm{O}_{3}$ milling balls ( 0.8 to $3.0 \mathrm{~cm}$ in diameter) in a 2-liter polyethylene bottle for $20 \mathrm{hr}$. The suspension was then held at about 80 Torr pressure for $1 \mathrm{hr}$ to remove air bubbles from the suspension. Glass rings $(5 \mathrm{~cm}$ crosssection, $1 \mathrm{~cm}$ thick) were placed on a flat plate and both rings and plate coated with a compacted layer of $\alpha-\mathrm{Al}_{2} \mathrm{O}_{3}$ powder, to prevent cracking of the wet $\alpha-\mathrm{Al}_{2} \mathrm{O}_{3}$ cake during

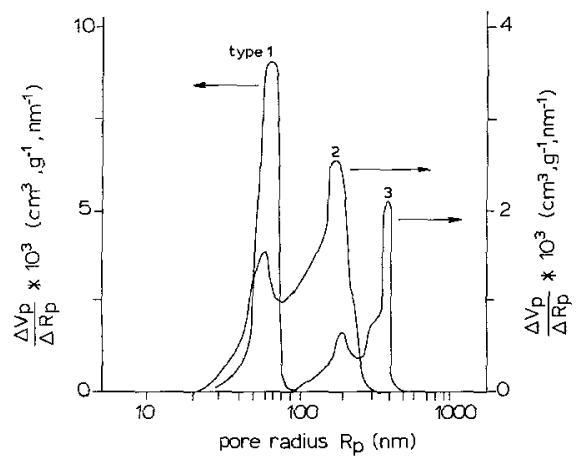

FrG. 1. Pore size distributions of the support materials used. Modal pore sizes and porosities are as follows: Type 1: $0.12 \mu \mathrm{m}, 46 \%$. Type 2: $0.34 \mu \mathrm{m}, 60 \%$. Type 3: $0.8 \mu \mathrm{m}, 45 \%$.

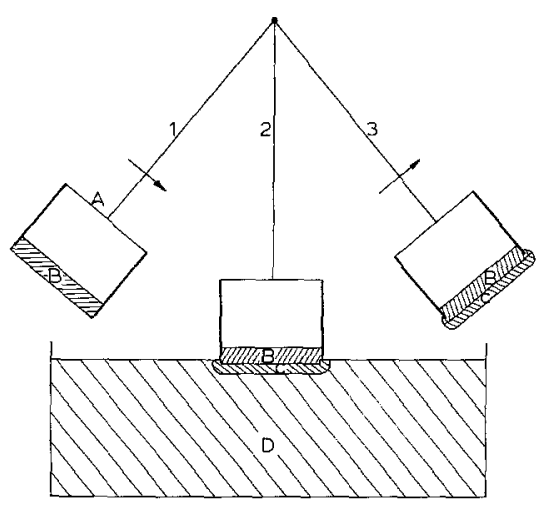

FIG. 2. Schematic presentation of the 3 stages of the dipping process.

drying later on. The $\alpha-\mathrm{Al}_{2} \mathrm{O}_{3}$ suspension ( $\mathrm{pH}$ 5.1) was poured into these glass-rings and dried. The dried samples were sintered at $1350^{\circ} \mathrm{C}$ for $16 \mathrm{hr}$ and brought into their final form.

The preparation of supported membranes is performed by a dipping procedure, presented schematically in Fig. 2. In situation 1 a porous ceramic support B is held in holder A. In situation 2 one side of this support is brought into contact with the boehmite sol D. The sol is sucked into the support by the capillary forces exerted by the pores of the support. When these pores are small enough, the boehmite particles cannot enter with the same velocity as the dispersion medium and the concentration of boehmite at the entrance of the pores will then increase. At a certain concentration of sol particles, the sol will be converted into a gel (C). After a certain period of contact between the support and the sol which can be defined within $0.5 \mathrm{sec}$, the support is removed from the sol (situation 3 ).

After dipping, the supported gel layers were dried overnight and then calcined at a rate of $10^{\circ} \mathrm{C}$ per hour up to a final temperature of $500^{\circ} \mathrm{C}$. In order to determine the layer thickness of the membranes thus formed, the supported membranes were broken and placed in an epoxy resin (Struers Scientific Instruments) in such a way that the flat membrane surface made a contact 
angle of $90^{\circ}$ with the surface of the resin. After hardening of the resin, the sample was polished and the membrane thickness measured using a JEOL-JSM 35 CF Scanning Electron Microscope.

The filtration experiments described in Section 3.5 were performed with the stirred dead-end permeation vessel shown in Fig. 3. To perform the filtration of boehmite sols, the stirrer was removed and a support was placed at position 8 . First the support and the outlet of the system were saturated with water by "filtering" water. The permeation vessel was then opened from the top, completely dried from above, and a known amount of sol $\left(2\right.$ or $3 \mathrm{~cm}^{3}$ ) introduced and filtration started. As a result of this procedure, the amount of permeate could be accurately determined and because it was obtained dropwise $\Delta V / \Delta t$ could be calculated. The volume of one drop equals $0.0396 \pm 0.0004$ $\mathrm{cm}^{3}$. The effective surface of the support during filtration is $8.87 \pm 0.1 \mathrm{~cm}^{2}$. These

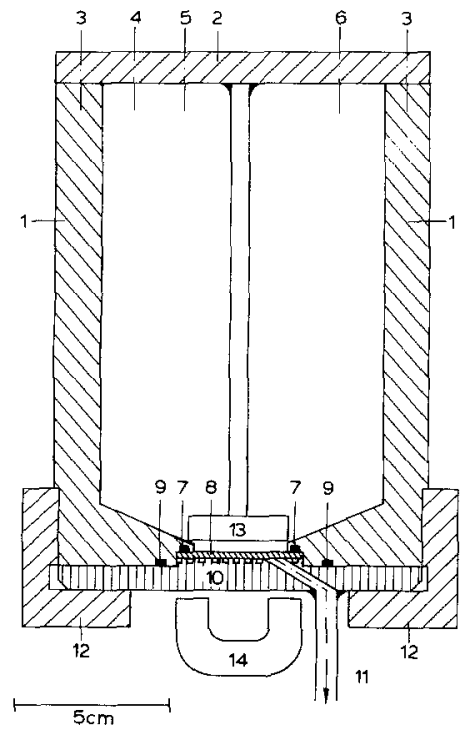

FIG. 3. Permeation vessel used for the filtration experiments. 1, Housing; 2, top plate; 3 , screws; 4, safety valve; 5 , connection with $\mathrm{N}_{2}$-gasholder; 6 , pressure gauge; 7 and 9, O-rings; 8, supported membrane or support; 10 , bottom plate; 11 , outlet; 12 , part screwed on housing; 13, magnetic stirrer; 14 , rotating magnet.
TABLE I

The Influence of the Type of Support (Pore Size) and the Peptising Acid on the Formation of Gel Layers during Dipping $^{a}$

\begin{tabular}{cccc} 
& \multicolumn{3}{c}{ Peptising acid used } \\
\cline { 2 - 4 } Support (type) & $\mathrm{HCl}$ & HNO, & $\mathrm{HClO}_{4}$ \\
\hline $1(0.12 \mu \mathrm{m})^{b}$ & Yes & Yes & Yes \\
$2(0.34 \mu \mathrm{m})^{b}$ & Yes & Yes & No \\
$3(0.8 \mu \mathrm{m})^{b}$ & Yes & No & No \\
\hline
\end{tabular}

${ }^{a}$ Yes, gel layer formed; no, no gel layer formed.

${ }^{b}$ Modal pore size given in parentheses.

experiments were performed at 10 and 15 bar filtration pressure, with type 1 supports.

\section{RESULTS AND DISCUSSION}

\subsection{Preliminary Dipping Experiments}

The main parameters determining whether or not a gel layer is formed during dipping are (1) the sol concentration, (2) the dipping time, (3) the pore size of the support, and (4) the type and amount of acid used to peptise the sol. When a type 1 or type 2 support is dipped into a $\mathrm{HNO}_{3}$ stabilized boehmite sol having a sol concentration of $0.5 \mathrm{~mole} / \mathrm{liter}$, a gel layer is formed. However no gel layer is formed when the sol concentration is lowered to $0.1 \mathrm{~mole} / \mathrm{liter}$. Only in some limiting cases is the dipping time a factor determining whether or not a gel layer will be formed (see below). The effect of the pore size of the support and the type of acid used are shown in Table $\mathrm{I}$, for a $\mathrm{HNO}_{3}$ stabilized sol with 1.22 mole/liter.

The results presented above can be qualitatively comprehended if the gel formation process is considered as a filtration process as described by Hermans and Bredée (5). When the boehmite particles enter the support during filtration (i.e., dipping), a socalled pore clogging mechanism is operative. Should the boehmite particles form a filter cake (i.e., gel) on the support due to gelation, a so-called cake filtration situation is present. If the concentration of solids in the sol is 
low, the filtration process starts with pore clogging. Due to this pore clogging, the pore size of the support is reduced and at a certain stage the pores will become so small that cake formation starts $(5,6)$. This pore clogging period is shortened when the concentration of solids increases (6). This explains the observations that gel formation is absent at low sol concentrations ( 0.1 mole/liter). In this case the cake formation step is not reached, because the support is saturated with the dispersion (and therefore the capillary pressure drop disappears), before cake filtration is obtained. At somewhat higher sol concentrations only long dipping times result in a gel formation process because pore clogging precedes cake formation, whereas at high sol concentrations ( $\geqslant 0.5$ mole/liter) cake filtration starts immediately.

Table I can be understood, if the decrease in turbidity in the series $\mathrm{HCl}^{-}, \mathrm{HNO}_{3}{ }^{-}$, $\mathrm{HClO}_{4}$-boehmite sols is taken into account. This decrease in turbidity is caused by a decrease in the size of the boehmite particles (7). The fundamental parameter which is varied as shown in Table $I$ is therefore the ratio of the boehmite particle size to the pore size of the support. When the boehmite particles (aggregates) are relatively large and the pores relatively small, gel formation takes place whereas this does not occur when the particles are small and the pores are large.

Another remarkable observation was that with a freshly prepared $\mathrm{HNO}_{3}$-stabilized sol of 0.5 mole/liter, no gel layers could be formed on type 2 supports, whereas aging of this sol during 1 week at room temperature results in the formation of gel layers under these dipping conditions. This might be the result of an increase of the agglomeration degree of the boehmite sol with time as found by Ramsay et al. [8]. They performed scattering experiments and drew the conclusion that boehmite with a BET surface area of $190 \mathrm{~m}^{2} \mathrm{~g}^{-1}$ and stabilized with more than 0.02 mole $\mathrm{HNO}_{3}$ per mole boehmite shows a slow increase of the agglomeration degree with time.
An example of a calcined supported $\gamma$ $\mathrm{Al}_{2} \mathrm{O}_{3}$ membrane obtained by dipping is given in Fig. 4. It appears that the membrane thickness can be clearly defined. If the membrane thickness of one sample is determined at a large number of places, some scattering of data is found as a result of the surface roughness of the support. However, the average values of the layer thickness of different samples of one membrane differ less than $0.5 \mu \mathrm{m}$ from one another, which shows that this average layer thickness is well defined.

When dipping parameters are chosen in such a way that cake filtration occurs immediately, the dipping time becomes a very critical parameter. Dipping times of a few seconds give gel layers which can be dried and calcined crack-free, whereas longer dipping times result in cracked membranes after calcination. The influence of the dipping time (Section 3.2) and a few other parameters (Section 3.6) on the gel formation process was investigated systematically, in order to obtain a better insight in the gel formation mechanism and because the process is a critical one.

\subsection{The Effect of the Dipping Time on the Membrane Layer Thickness}

Boehmite sols with a sol concentration of 0.72 and 1.22 mole/liter, respectively, were used for dipping type 2 supports during 1$11 \mathrm{sec}$. The results are given in Table II. It appeared that all membranes with a thickness larger than $5 \mu \mathrm{m}$ show some cracks after calcination.

The layer growth as a function of system and process parameters will be described further on by considering the dipping process in terms of the co-called slibcasting process. The slibcasting process is used for example to prepare ceramics with complex shapes from suspensions by pouring the suspension into a porous mold of the desired shape (9, $10)$. Both the dipping process and the slibcasting process make use of the capillary action of the porous support to form a filter 


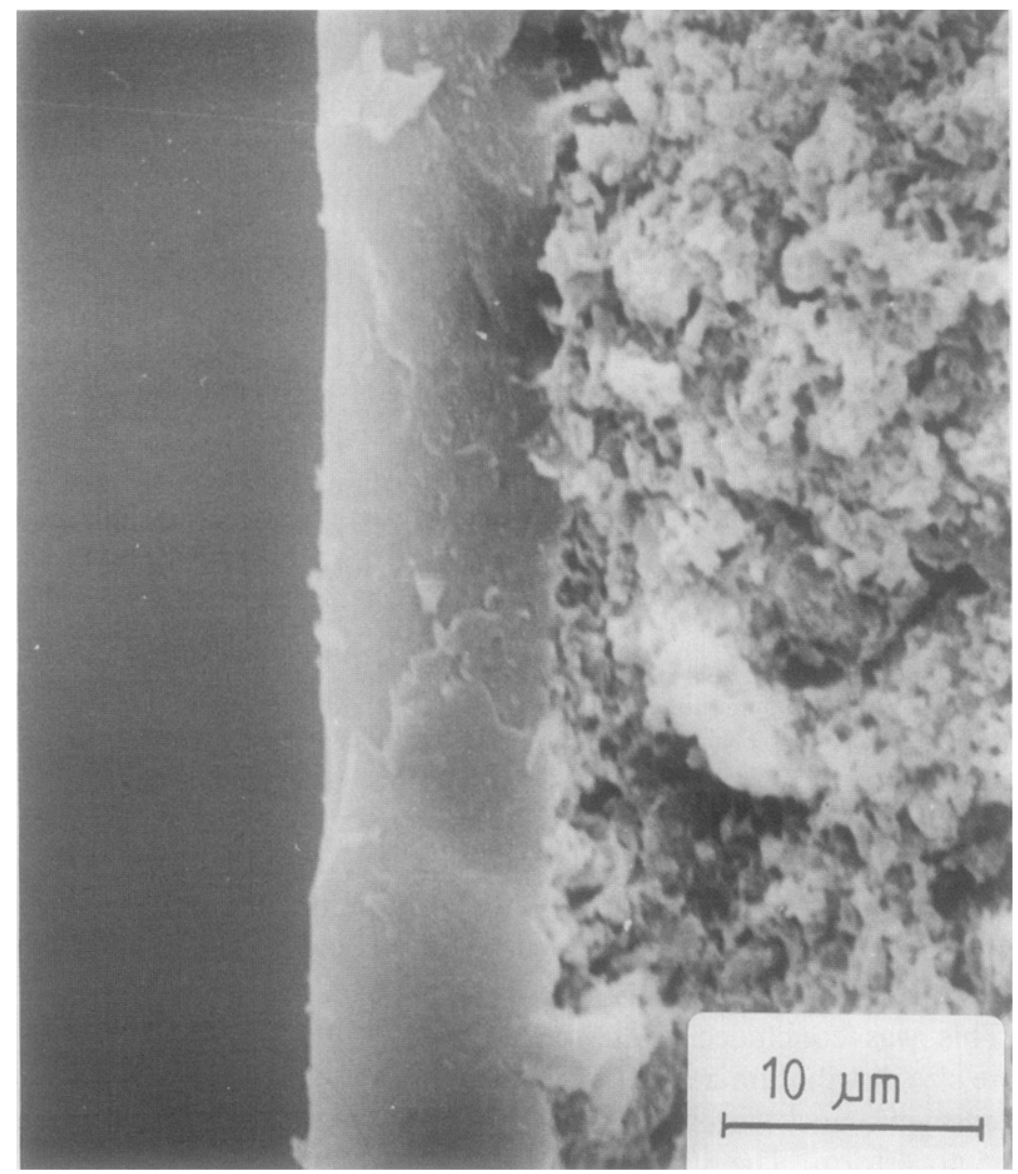

FIG. 4. Fracture surface of a supported $\gamma-\mathrm{Al}_{2} \mathrm{O}_{3}$ membrane.

cake. The most important differences between the two processes are that the boehmite crystallites are much smaller than those normally

\section{TABLE II}

The Layer Thickness of Calcined Membranes as a Function of the Dipping Time, for Type 2 Supports and Sols with 0.72 and 1.22 mole Boehmite/liter, Respectively

\begin{tabular}{ccc}
\hline & \multicolumn{2}{c}{ Membrane thickness $(\mu \mathrm{m})$} \\
\cline { 2 - 3 } $\begin{array}{c}\text { Dipping time } \\
\text { (sec) }\end{array}$ & $\begin{array}{c}0.72 \text { Mole } \\
\text { boehmite/liter }\end{array}$ & $\begin{array}{c}1.22 \text { Mole } \\
\text { boehmite/liter }\end{array}$ \\
\hline 1 & 3.0 & 3.2 \\
3 & 4.0 & 5.8 \\
5 & 6.0 & 6.8 \\
7 & - & 7.8 \\
11 & 8.0 & - \\
\hline
\end{tabular}

used in slibcasting (the surface area of the boehmite crystallites is $359 \mathrm{~m}^{2} \mathrm{~g}^{-1}$ (1) and the boehmite gel layer formed has a much lower density than the cast obtained by the normal slibcasting process (see Section 3.5). A characteristic feature of the slibcasting process is that the layer thickness of the cast increases linearly with the square root of the casting time (10-12). This relation also holds for the dipping process as is shown in Fig. 5. The straight lines are obtained by least squares analyses of the experimental results.

In the slibcasting model the thickness of the wet filter cake is considered, whereas here the thickness of the calcined layers is taken. This is permitted, because the degree of shrinkage of the wet gel layer is independent 


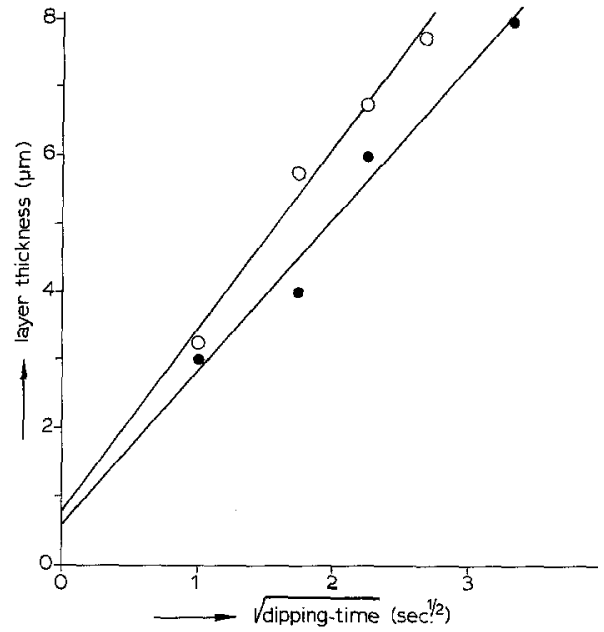

FIG. 5. The membrane thickness after calcination plotted as the square root of the dipping time, for type 2 supports. (closed circles: 0.72 mole boehmite/liter and open circles: 1.22 mole/liter.

of its thickness, as can be shown as follows. The structure of the calcined membranes does not depend on the thickness of the membranes. This was concluded from the unchanged pore size distribution and porosity of nonsupported membranes with a thickness varying from 5 to $40 \mu \mathrm{m}$. The structure of the gels obtained by dipping is also independent of their thickness (see Section 3.4). Therefore the ratio between the layer thicknesses of the gel layers before and after drying and calcination can be represented by a constant factor and is independent of the gel layer thickness.

The lines in Fig. 5 do not pass through the origin. This can be explained by taking into account that a thin sol layer adheres to the gel layer when the support is taken out of the sol. A part of the total gel layer thickness will result from this adhered sol layer and because the effect of this mechanism is independent of the dipping time, the lines are shifted upward but the slopes remain unchanged. The intersection of the lines with the vertical axis, therefore represents the effect caused by the adhered sol layer. This effect on the layer thickness was determined semiquantitatively by dipping a nonporous $\alpha$ $\mathrm{Al}_{2} \mathrm{O}_{3}$ support into the sols used and measuring the adhered amount of sol by weighing. The corresponding membrane thickness was calculated, using the amount of sol, the sol concentration, the weight loss during calcination (due to the transformation of $\gamma$-AlOOH into $\gamma-\mathrm{Al}_{2} \mathrm{O}_{3}$ ), the density of $\gamma-\mathrm{Al}_{2} \mathrm{O}_{3}$ (i.e., $\left.3.7 \mathrm{~g} \mathrm{~cm}^{-3}(4)\right)$ and a porosity of the calcined layer of $54 \%$ (1). Values of 0.7 and $1.1 \mu \mathrm{m}$ were obtained for the sols with a concentration of 0.72 and 1.22 mole/liter, respectively. These values correspond reasonably well with the parts of the vertical axis cut by the lines in Fig. 5 and they give the minimum thickness achievable by the dipping method.

When experiments with a longer dipping time than the values given in Table II are performed, the gel layer breaks up into parts which are too small to yield an accurate determination of the layer thickness. It was observed however, that after a much longer dipping time the gel layer peels off the support during drying and breaks into large pieces of which the layer thickness could be easily determined. This phenomenon was used to check whether the relation shown in Fig. 5 would hold in the case of a long dipping time. It was found that dipping for $120 \mathrm{sec}$ in the boehmite sol with 1.22 mole/liter gives a calcined membrane thickness of $32 \mu \mathrm{m}$. This fits well with $30.5 \mu \mathrm{m}$ obtained by extrapolating the corresponding straight line in Fig. 5.

Summarizing, we can conclude that the membrane thickness increases linearly with the square root of the dipping time. This dependence is predicted by the slibcasting process and it is therefore worthwhile to conduct a detailed analysis of this process.

\subsection{Theoretical Analysis of the Dipping Process from the Viewpoint of Slibcasting}

Equations describing the slibcasting process will be derived in this section. Although a 
derivation which strongly resembles the following one has been previously presented by Dal and Berden (12), the essential steps are given here, to show clearly the assumptions which are made. The model obtained is then compared with the dipping results in Sections 3.4-3.6.

A support is considered with a surface area of $1 \mathrm{~m}^{2}$, on which the gel layer is formed. During slibcasting the situation as given in Fig. 6 will occur. A gel layer with a thickness $L_{\mathrm{g}}$ is formed on the support. The support consists of a part with a thickness $L_{\mathrm{s}}$ that is completely saturated with the liquid from the dispersion, and a dry part, the menisci in the boundary zone generating the pressure that drives the casting process. The capillary pressure drop $\left(\Delta P_{\mathrm{c}}\right)$ is caused by cylindrical pores with a radius $R$ and for each capillary the following equation holds:

$$
\Delta P_{\mathrm{c}}=\frac{2 \gamma}{R} \cos \beta
$$

in which $\gamma$ represents the surface tension of the liquid in the pores of the support. $\beta$ is the contact angle between the liquid and the solid surface and is assumed to be zero degrees. The total pressure drop can be divided into one part caused by the gel layer $\left(\Delta P_{\mathrm{g}}\right)$ and another part caused by the saturated layer of the support $\left(\Delta P_{\mathrm{s}}\right)$.

Therefore the following equation holds, which is also shown in Fig. 6.

$$
\Delta P_{\mathrm{g}}=\Delta P_{\mathrm{c}}-\Delta P_{\mathrm{s}}
$$

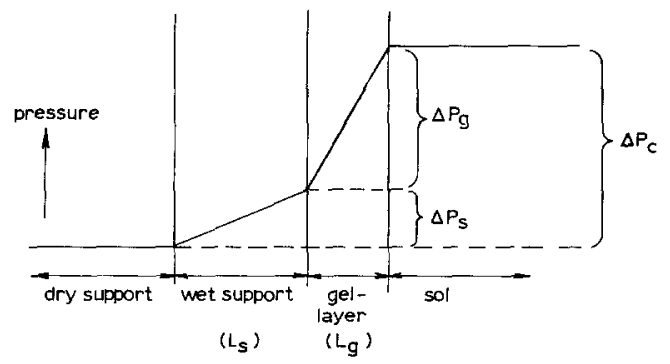

FIG. 6. The pressure drop at a certain stage of the casting process.
The amount of boehmite sol which is necessary to obtain a gel layer with a thickness $L_{\mathrm{g}}$ and a saturated layer of the support $L_{\mathrm{s}}$ is $L_{\text {sol }}$. Simple mass balance considerations show that

$$
L_{\mathrm{sol}}=L_{\mathrm{g}}+\theta_{\mathrm{s}} L_{\mathrm{s}} .
$$

The sol particles are only present in the sol with a volume fraction $C$ and in the gel layer with a volume fraction $\left(1-\theta_{\mathrm{g}}\right)$ and therefore

$$
L_{\mathrm{sol}} C=L_{\mathrm{g}}\left(1-\theta_{\mathrm{g}}\right) \text {. }
$$

Combining [3] and [4] gives

$$
\frac{\left(1-\theta_{\mathrm{g}}\right)}{C}=\alpha+1
$$

where $\alpha$ is defined as

$$
\alpha=\frac{\theta_{\mathrm{s}} L_{\mathrm{s}}}{L_{\mathrm{g}}}
$$

The volume of liquid that has passed the gel layer and is present in the support is equal to $V$ :

$$
V=\theta_{\mathrm{s}} L_{\mathrm{s}}=\alpha L_{\mathrm{g}}
$$

Applying D'Arcy's equation to the gel layer gives

$$
\frac{d V}{d t}=\frac{\Delta P_{\mathrm{g}} K_{\mathrm{g}}}{\eta L_{\mathrm{g}}}
$$

where $d V / d t$ is the velocity of the liquid flow through the gel layer, $K_{\mathrm{g}}$ is the permeability constant of the gel layer and $\eta$ is the viscosity of the liquid. Combining Eqs. [7] and [8] and integrating the result under the boundary condition that $L_{\mathrm{g}}=0$ at $t=0$, gives

$$
L_{\mathrm{g}}=\left\{\frac{2 K_{\mathrm{g}} \Delta P_{\mathrm{g}} t}{\eta \alpha}\right\}^{1 / 2} \text {. }
$$

To obtain $\Delta P_{\mathrm{g}}$ as a function of system parameters, the flow resistance of the support should be considered. According to Poiseuille the volume flux through the pores of the support is given by 


$$
\frac{d V}{d t}=\theta_{\mathrm{s}} \frac{R^{2} \Delta P_{\mathrm{s}}}{8 k_{\mathrm{t}} \eta L_{\mathrm{s}}}
$$

where $\theta_{\mathrm{s}}$ and $k_{\mathrm{t}}$ are introduced to correct for the surface area of the nonporous part of the support and the tortuosity, respectively. In fact the surface fraction of pores should be introduced in Eq. [10], but it has been shown that the volume fraction of pores serves equally well (15). Eliminating $V$ with Eq. [7] and $\Delta P_{\mathrm{s}}$ with Eqs. [1] and [2] and taking a factor 2.5 for the tortuosity we obtain

$$
\frac{d L_{\mathrm{s}}}{d t}=\frac{R^{2}}{20 \eta L_{\mathrm{s}}}\left\{\frac{2 \gamma}{R}-\Delta P_{\mathrm{g}}\right\} \text {. }
$$

Integration under the boundary condition that $L_{\mathrm{s}}=0$ at $t=0$ and elimination of $L_{\mathrm{s}}$ with Eq. [7] gives

$$
L_{\mathrm{g}}^{2}=\frac{\theta_{s}^{2}}{\alpha^{2}} \frac{R^{2}}{10 \eta}\left\{\frac{2 \gamma}{R}-\Delta P_{\mathrm{g}}\right\} t .
$$

Elimination of $L_{\mathrm{g}}$ with Eq. [9] and rearranging finally gives

$$
\Delta P_{\mathrm{g}}=\frac{2 \gamma}{R}\left\{\frac{1}{1+\frac{20 K_{\mathrm{g}} \alpha}{\theta_{\mathrm{s}}^{2} R^{2}}}\right\} .
$$

The most important assumptions that have been made are in summary:

(1) The sol particles are only present on top of the support, i.e., only so-called cake filtration takes place.

(2) The gel layer has a homogeneous composition as can be shown for example by the linear pressure drop in the gel layer in Fig. 6.

(3) The capillary pressure drop is calculated from one type cylindrical pore and not from a pore size distribution, and $\beta$ (of Eq. [1]) is assumed to be zero degrees.

Finally it should be noted that Eq. [9] corresponds with the so-called filtration equation, which is applicable when cake filtration takes place under influence of an externally applied pressure $(11,13)$.

\subsection{The Gel Formation Process Calculated with the Slibcasting Model}

The linear relation between the membrane thickness and the square root of the dipping time found in Fig. 5 implies that the structure of the gel layer is homogeneous. This is quite remarkable, because the steepness of the pressure drop decreases with increasing dipping time $\left(\Delta P_{\mathrm{g}}\right.$ remains constant and $L_{\mathrm{g}}$ increases, see Fig. 6) and $1-\theta_{\mathrm{g}}$ has quite low values of $0.2-0.3$ (see Section 3.5). Apparently, this decrease in the steepness of the pressure drop in time has no influence on the degree of compaction of the rather porous gel layer.

The thickness of the gel layer $L_{\mathrm{g}}$ obtained by dipping can be calculated with Eqs. [9] and [13], if $R, \theta_{\mathrm{s}}, \gamma, \eta, t, K_{\mathrm{g}}$, and $\alpha$ are known. This calculation is performed for the type 1 support, taking $6.10^{-8} \mathrm{~m}$ for $R$ and 0.46 for $\theta_{\mathrm{s}}$. For $\gamma$ and $\eta$ the values of water at $20^{\circ} \mathrm{C}$ are used, i.e., $72.8 \times 10^{-3} \mathrm{~N} \mathrm{~m}^{-1}$ and $10^{-3} \mathrm{~N} \mathrm{~m}^{-2} \mathrm{sec}$, respectively (14). Because $t$ is put at $60 \mathrm{sec}$, only $K_{\mathrm{g}}$ and $\alpha$ remain unknown. According to the Kozeny-Carman equation (15), $K_{\mathrm{g}}$ is equal to

$$
K_{\mathrm{g}}=\frac{\theta_{\mathrm{g}}^{3}}{k_{0} k_{\mathrm{t}} S_{\mathrm{v}}^{2}\left(1-\theta_{\mathrm{g}}\right)^{2}}
$$

where $k_{0}$ and $k_{\mathrm{t}}$ are system constants accounting for the shape of the pores and the tortuosity, respectively. The product of $k_{0}$ and $k_{\mathrm{t}}$ was put at 5 , a value which is commonly used. $S_{\mathrm{v}}$ is the surface area per unit volume of solid boehmite and is obtained by taking $359 \mathrm{~m}^{2} \mathrm{~g}^{-1}$ (1) and $3 \mathrm{~g} \mathrm{~cm}^{-3}$ (4), for the surface area and the density, respectively. If the gelling concentration $1-\theta_{\mathrm{g}}$ is known, $K_{\mathrm{g}}$ can be calculated with Eq. [14] and $\alpha$ with Eq. [5], putting $C$ at 1.22 mole/liter. No reasonable theoretical estimate can be made for $1-\theta_{\mathrm{g}}$ at this point and therefore $L_{\mathrm{g}}$ was calculated for different assumed gelling concentrations. The layer thicknesses of the calcined membranes were calculated from $L_{\mathrm{g}}$, assuming a porosity of $54 \%$ and a true 
density of $3.7 \mathrm{~g} \mathrm{~cm}^{-3}$ for the calcined $\gamma-$ $\mathrm{Al}_{2} \mathrm{O}_{3}$ membranes (1). The results of the calculations are given in Table III. As shown in Section 3.6, dipping under the same conditions as used for the calculations gives a calculated membrane thickness of $35 \mu \mathrm{m}$. If a correction of $0.8 \mu \mathrm{m}$ is applied for the sol layer adhered to the gel layer (see Section 3.2 and Fig. 5), $34.2 \mu \mathrm{m}$ is obtained. This experimental value falls within the range given in Table III.

\subsection{Checks on the Assumptions Made in the Calculations of Section 3.4}

To check the assumptions made in the calculations, $\alpha, \Delta P_{\mathrm{g}}$, and $K_{\mathrm{g}}$ were determined experimentally, by performing filtration experiments with type 1 supports in a pressure vessel as described in Section 2. The pressure and the amount of filtrate $\left(\theta_{\mathrm{s}} L_{\mathrm{s}}\right)$ can then be accurately determined.

In principle $\alpha$ can be determined experimentally with Eqs. [3] and [6], if the amount of permeate, which corresponds with $\theta_{\mathrm{s}} L_{\mathrm{s}}$ in Eq. [3], is known at the point where the added amount of sol is completely converted into a gel. It was however difficult to define the end point of filtration, as a result of two complications:

(1) After the gel formation process was completed at the center of the support, the region close to the O-ring 7 (see Fig. 3) still contained some sol.

(2) After the gel formation process was completed on the entire support, permeate was still obtained, probably as a result of a gel compaction process. The rate of this process was very slow: $d V / d t$ being about 10 times smaller than cake filtration at a corresponding time $t$ would be.

In order to account for these complications a trial-and-error method was used. A series of experiments were performed with increasing filtration times. After each experiment the state of the gel formation was observed and the shortest filtration time by which the gel formation was completed was taken. By this method the gelling concentration determined was 11-13 mole/liter, at both filtration pressures $\left(\Delta P_{\mathrm{f}}\right)$ of 10 and 15 bar. A gelling concentration up to $17 \mathrm{~mole} / \mathrm{liter}$ however might be possible, because of the uncertainties mentioned above. The increase from 13 to 17 mole/liter is caused by only one extra drop of permeate.

The determination of $\Delta P_{\mathrm{g}}$ was performed as follows. At the moment the gel formation process was completed at the center of the support (which could be easily judged from deviations from straight lines as shown in Fig. 7, see below), the filtration was stopped. The gel was dried and calcined and the layer

TABLE III

Parameters Calculated with the Slibcasting Model for Different Gelling Concentrations ${ }^{a}$

\begin{tabular}{cccccc}
\hline $\begin{array}{c}\text { Gelling concentration } \\
\text { (mole/liter) }\end{array}$ & $\begin{array}{c}K_{\mathbf{z}} \times 10^{19} \\
\left(\mathrm{~m}^{2}\right)\end{array}$ & $\begin{array}{c}\Delta P_{z} \times 10^{-5} \\
\left(\mathrm{~N} \mathrm{~m}^{-2}\right)\end{array}$ & $\begin{array}{c}\Delta P_{z} / \Delta P_{c}^{b} \\
(-)\end{array}$ & $\begin{array}{c}L_{z} \\
(\mu \mathrm{m})\end{array}$ & $\begin{array}{c}\text { Calcined membrane } \\
\text { thickness }(\mu \mathrm{m})\end{array}$ \\
\hline 9 & 29 & 16 & 0.67 & 300 & 81 \\
11 & 17 & 18 & 0.74 & 210 & 70 \\
13 & 10 & 19 & 0.79 & 160 & 61 \\
15 & 6.6 & 20 & 0.84 & 120 & 54 \\
17 & 4.3 & 21 & 0.87 & 92 & 47 \\
19 & 2.8 & 22 & 0.90 & 72 & 31 \\
21 & 1.9 & 23 & 0.93 & 56 & 35 \\
23 & 1.3 & 23 & 0.94 & 44 & 31 \\
\hline
\end{tabular}

${ }^{a}$ Dipping time of $60 \mathrm{sec}$ with type 1 supports in a sol with 1.22 mole boehmite/liter.

${ }^{b}$ Fraction of the total pressure drop present over the gel layer. 


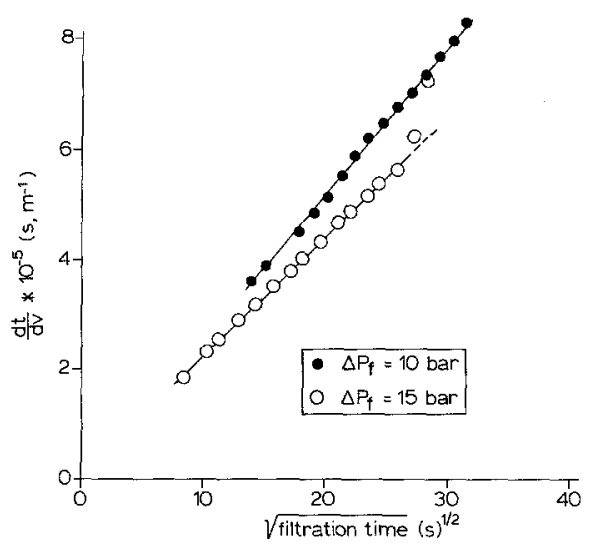

FIG. 7. The flow resistance of the gel/support system as a function of the square root of the filtration time. (type 1 supports).

thickness at the center of the membrane determined (i.e., $L_{\text {calcined }}$ ). The effective pressure during dipping $\left(\Delta P_{\mathrm{g}}\right)$ was then obtained from

$$
\begin{aligned}
\Delta P_{\mathrm{g}}=\left\{\frac{\left(\frac{t}{60}\right)^{1 / 2} \times 34.2}{L_{\text {calcined }}}\right\}^{2} & \\
& \times\left\{\Delta P_{\mathrm{f}}-5 \times 10^{4}\right\} .
\end{aligned}
$$

Here $t$ is the filtration time. The corrected calcined layer thickness obtained by dipping during 60 secs is $34.2 \mu \mathrm{m}$ (see Section 3.6). Therefore the numerator represents the layer thickness that would be obtained during dipping for $t$ seconds (see Eq. [9]). The ratio of this calculated layer thickness and that measured should be squared, because the layer thickness depends linearly on the square root of the dipping pressure. The value of $\Delta P_{\mathrm{f}}$ is diminished by $5 \times 10^{4} \mathrm{~N} \mathrm{~m}^{-2}$ as correction for the flow resistance of the support. The results are $L_{\text {calcined }}=142 \mu \mathrm{m}$ at $t=1145 \mathrm{sec}$ with $\Delta P_{\mathrm{f}}=10$ bar and $L_{\text {calcined }}=129 \mu \mathrm{m}$ at $t=840 \mathrm{sec}$ with $\Delta P_{\mathrm{f}}=15$ bar. Inserting these results in Eq. [15] gives $\Delta P_{\mathrm{g}}$ values of 10 and 14 bar for 10 and 15 bar filtration pressure, respectively. These values are significantly lower than those calculated and given in Table III. Some reasons for this deviation are given in the last part of Section 3.3 (point 3).

$K_{\mathrm{g}}$ was determined experimentally from the kinetic data of the filtration process, according to a method similar to that used in the literature $(5,13)$. If D'Arcy's equation, which is Eq. [8] here, is applied to the gel layer and support, while assuming that the two flow resistances can be connected in series, the following relation can be derived:

$$
\frac{d V}{d t}=\frac{\Delta P_{\mathrm{f}}}{\frac{\eta L_{\mathrm{g}}}{K_{\mathrm{g}}}+\frac{\eta L_{\mathrm{s}}}{K_{\mathrm{s}}}}
$$

where $K_{s}$ is the permeability of the support. Combining Eqs. [9] and [16] gives

$$
\frac{d t}{d V}=\left\{\frac{2 \eta \Delta P_{\mathrm{g}}}{K_{\mathrm{g}} \Delta P_{\mathrm{f}}^{2} \alpha}\right\}^{1 / 2} \times t^{1 / 2}+\frac{\eta L_{\mathrm{s}}}{K_{\mathrm{s}} \Delta P_{\mathrm{f}}} .
$$

The experimental results are given in Fig. 7. Here $d t / d V$ is plotted as a function of $t^{1 / 2}$ and the straight lines prove that cake filtration takes place $(5,11,13)$. The upward deviation from the lines at long filtration times indicate that gel formation is completed at the center of the support. The slope of the lines is equal to

$$
\left\{\frac{2 \eta \Delta P_{\mathrm{g}}}{K_{\mathrm{g}} \Delta P_{\mathrm{f}}^{2} \alpha}\right\}^{1 / 2}
$$

By subtracting 0.35 bar from $\Delta P_{\mathrm{f}}$ to account for the flow resistance of the support, $\Delta P_{\mathrm{g}}$ is found and $K_{\mathrm{g}} \alpha$ is then obtained. This gives $K_{\mathrm{g}} \alpha=3.0 \times 10^{-18} \mathrm{~m}^{2}$ both for $\Delta P_{\mathrm{f}}=10$ and 15 bar. The $K_{\mathrm{g}}$ values for gelling concentrations of $11(\alpha=8.0), 13(\alpha=9.7)$, and 17 mole/liter $(\alpha=13.0)$ are $3.8 \times 10^{-19}, 3.1$ $\times 10^{-19}$, and $2.3 \times 10^{-19} \mathrm{~m}^{2}$, respectively. Comparison of these data with the corresponding values in Table III shows that the measured values are 1.9 to 4.5 times lower than the calculated $K_{\mathrm{g}}$ values. The following factors contribute to a lower value of $K_{\mathrm{g}}$ than calculated in Section 3.5:

(1) The boehmite crystallites are plateshaped (1). This may result in a higher value 
of the tortuosity $k_{\mathrm{t}}(15)$, which in turn causes a decrease in $K_{\mathrm{g}}$ (see Eq. [14]).

(2) As a result of a liquid flow through a porous system with charged walls, a streaming potential will be present. This streaming potential has a retarding influence on the liquid flow (the so-called electroviscous effect). According to the literature $(16-18)$, this effect will only diminish the liquid flow by less than $30 \%$.

(3) A strong increase of the viscosity of the liquid. A 10 times higher viscosity than that of bulk water was found by Belfort in Vycor glass with a high charge density and a pore size of $2.5 \mathrm{~nm}(19,20)$. He attributed this effect to the fact that the water was more or less bound to the glass surface.

Summarizing the results presented above, it appears that the gelling concentration is between 11 and 17 mole/liter, $\Delta P_{\mathrm{g}}$ is about 12 bar and $K_{\mathrm{g}}$ is $2.3-3.8 \times 10^{-19} \mathrm{~m}^{2}$. The layer thickness calculated with these values along the same lines as was carried out in Section 3.4 is $27 \mu \mathrm{m}$, which is close to the experimental value of $34 \mu \mathrm{m}$. Therefore we can state that the slibcasting model quantitatively describes the gel formation process quite well.

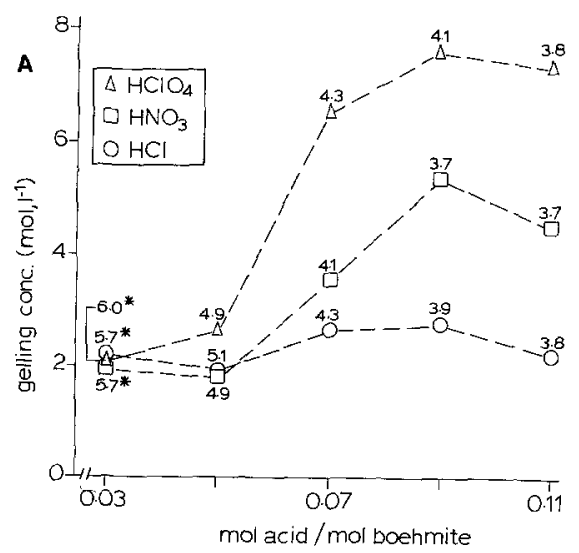

\subsection{The Influence of Some Experimental Parameters on the Gel Formation Process}

According to the slibcasting model, the influence of the sol concentration on the casting rate is determined by the square root of the ratio of the $\alpha$ values ( $\Delta P_{\mathrm{g}}$ decreases only very slightly with an increasing $\alpha$ here). For sols with a concentration of 0.72 and $1.22 \mathrm{~mole} / \mathrm{liter}$, the square root of this ratio is 1.3. This is in good agreement with the quotient of the slopes of the lines given in Fig. 5, which is also 1.3.

The slibcasting theory predicts a strong effect of the gelling concentration on the casting rate (see Table III). All factors which have an effect on this gelling concentration can therefore be used to manipulate the casting rate. The gelling concentration is known to depend on the acid/boehmite ratio (21) and we found that it is also affected by the type of acid used and the aging of the sol. The results given in Fig. 8 are obtained by peptising boehmite at $90-100^{\circ} \mathrm{C}$ with 0.03 mole acid per mole boehmite for about $1 \mathrm{hr}$ ("shortly aged" sols) or as is normal for 16 hr ("long aged" sols). The sols were then split into portions and a series of acid/boehmite ratios as given in Fig. 8 were made.

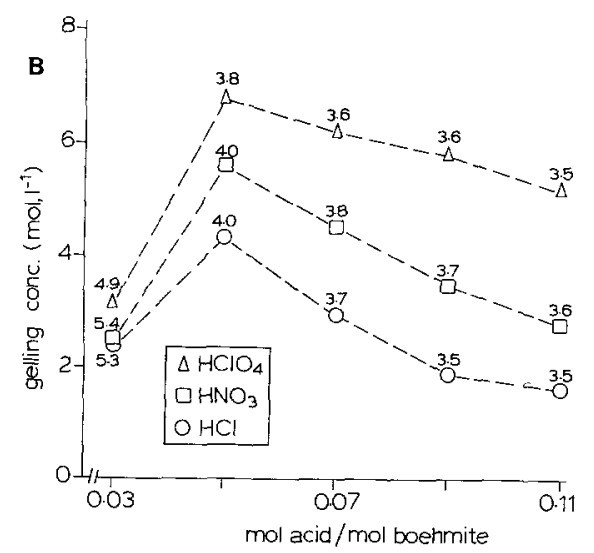

FIG. 8A. The sol concentration at the gelling stage of the sol as a function of the acid/boehmite ratio for shortly aged sols. The numbers near the experimental results represent the $\mathrm{pH}$ values.

FIG. 8B. The sol concentration at the gelling stage of the sol as a function of the acid/boehmite ratio for long-aged sols. The numbers near the experimental results represent the $\mathrm{pH}$ values. 
After boiling for half an hour, the $\mathrm{pH}$ was determined (at room temperature) and the sols were then concentrated by boiling for several hours till gelling occurred. The values of the gelling concentrations thus obtained will differ from those obtained during dipping, because the conditions are different. However an increase in gelling concentration under "boiling" conditions will most probably also result in an increase in gelling concentration under dipping conditions. The dependence of the casting rate on the gelling concentration was tested using thee long-aged boehmite sols with an acid/boehmite ratio of 0.07 mole/ mole, a concentration of 1.22 mole boehmite/ liter containing $\mathrm{HCl}, \mathrm{HNO}_{3}$, and $\mathrm{HClO}_{4}$, respectively. Type 1 supports were dipped in these sols for $1 \mathrm{~min}$. The results are given in Table IV. It indeed appears that the casting rate diminishes when the gelling concentration increases.

The effect of the pore size of the support was determined by taking type 1 and type 2 supports and dipping them for $60 \mathrm{sec}$ in a $1.22 \mathrm{~mole} /$ liter boehmite sol. The results given in Table IV show that the layer thickness decreases with an increasing pore size of the support. As shown in Table III, almost the entire pressure drop is caused by the gel layer. Therefore the influence of the pore size of the support on the casting rate is expected

\section{TABLE IV}

The Effect of the Type of Peptising Acid and the Type of Support on the Layer Thickness of Calcined Membranes $^{a}$

\begin{tabular}{lcc}
\hline $\begin{array}{c}\text { Peptising acid } \\
\text { (type) }\end{array}$ & $\begin{array}{c}\text { Support } \\
\text { (type) }\end{array}$ & $\begin{array}{c}\text { Membrane thickness } \\
(\mu \mathrm{m})\end{array}$ \\
\hline $\mathrm{HCl}$ & 1 & $38.1,41.5^{b}$ \\
$\mathrm{HNO}_{3}$ & 1 & $34.2,35.8^{b}$ \\
$\mathrm{HClO}_{4}$ & 1 & $22.6,23.6^{b}$ \\
$\mathrm{HNO}_{3}$ & 2 & $21.4,22.6^{b}$ \\
\hline
\end{tabular}

\footnotetext{
${ }^{a}$ All dippings during $60 \mathrm{sec}$ in sols with $1.22 \mathrm{~mole} /$ liter.

${ }^{b}$ Duplo-experiments.
}

to be almost equal to the square root of the ratios of the $\Delta P_{\mathrm{c}}$ values $\left(\Delta P_{\mathrm{c}}\right.$ is then about equal to $\Delta P_{\mathrm{g}}$ ). The square root of this ratio is 1.7 , being in good agreement with the observed ratio of the membrane thicknesses in Table IV, which is 1.6 .

\section{CONCLUSIONS}

(1) The preparation of crack-free supported alumina membranes from boehmite sols is a very critical process, as shown in Section 3.1. The most important parameters determining whether or not a gel is formed during dipping of the support into the sol are (a) the sol concentration, (b) the dipping time, (c) the pore size of the support, and (d) the type and amount of acid used to stabilize the sol.

(2) Crack-free alumina membranes can be obtained when the membrane thickness after calcination is not larger than $5 \mu \mathrm{m}$. Their production requires dipping times of the order of a few seconds, if the dipping conditions are so chosen that cake filtration (i.e., gel formation) starts immediately.

(3) The gel layer thickness increases linearly with the square root of the dipping time, indicating that a so-called slibcasting process is operative (Section 3.2).

(4) Equations describing the slibcasting model are derived in Section 3.3. The experimental value of the layer growth (casting rate) agrees reasonably well with the value obtained by calculations based on the slibcasting model (Sections 3.4-3.5). The value of $K_{\mathrm{g}}$ (the permeability of the gel layer) is 24.5 times lower than expected. Possible reasons are suggested.

(5) The influence of all dipping parameters investigated is in accordance with the slibcasting model (Section 3.6):

(a) With an increase in sol concentration, the casting rate increases from 2.2 to $2.8 \mu \mathrm{m} \mathrm{sec}-0.5$ for 0.72 to $1.22 \mathrm{~mole} / \mathrm{liter}$, 
respectively (for type 2 supports and $\mathrm{HNO}_{3}$-stabilized sols).

(b) In the series $\mathrm{HCl}-, \mathrm{HNO}_{3}-, \mathrm{HClO}_{4}$ boehmite sols, the gelling concentration increases. The casting rate decreases in the same order of this series and amounts to 5.0 and $2.8 \mu \mathrm{m} \mathrm{sec}{ }^{-0.5}$ for $\mathrm{HCl}$ - and $\mathrm{HClO}_{4}$ stabilized sols, respectively (for type 1 supports and sols with 1.22 mole boehmite/liter).

(c) If the modal pore size of the support is increased from $0.12 \mu \mathrm{m}$ (type 1 support) to $0.34 \mu \mathrm{m}$ (type 2 support), the casting rate will decrease from 4.4 to $2.8 \mu \mathrm{m} \mathrm{sec}{ }^{-0.5}$ for $\mathrm{HNO}_{3}$-stabilized sols with 1.22 mole boehmite/liter.

\section{APPENDIX NOMENCLATURE}

C Volume fraction of solids in the sol (-)

$K_{\mathrm{g}} \quad$ Permeability of the gel layer $\left(\mathrm{m}^{2}\right)$

$K_{\mathrm{s}} \quad$ Permeability of the support $\left(\mathrm{m}^{2}\right)$

$k_{0} \quad$ Part of the Kozeny-Carman constant accounting for the shape of the pores $(-)$

$k_{\mathrm{t}} \quad$ Part of the Kozeny-Carman constant accounting for the tortuosity of the pores (-)

$L_{\text {calcined }}$ Thickness of the calcined membrane (m)

$L_{\mathrm{g}} \quad$ Thickness of the wet gel layer (m)

$L_{\mathrm{s}} \quad$ Thickness of the saturated part of the support $(\mathrm{m})$

$L_{\text {sol }} \quad$ Thickness of the sol layer from which the gel layer is formed $(\mathrm{m})$

$\Delta P_{\mathrm{f}}$ Externally applied filtration pressure (N $\mathrm{m}^{-2}$ )

$\Delta P_{\mathrm{c}} \quad$ Capillary pressure drop over one pore of the support $\left(\mathrm{N} \mathrm{m}^{-2}\right)$

$\Delta P_{\mathrm{g}} \quad$ Pressure drop over the gel layer $\left(\mathrm{N} \mathrm{m}^{-2}\right)$

$\Delta P_{\mathrm{s}} \quad$ Pressure drop over the saturated part of the support $\left(\mathrm{N} \mathrm{m}^{-2}\right)$

$R \quad$ Radius of the pores of the support (m)

$S_{\mathrm{v}} \quad$ Surface area per unit volume solids $\left(\mathrm{m}^{-1}\right)$

$t \quad$ Dipping time/filtration time (sec)
$V \quad$ Total volume of liquid in $1 \mathrm{~m}^{2}$ support (m)

$\frac{d V}{d t}$ Liquid flow through $1 \mathrm{~m}^{2}$ surface area per second $\left(\mathrm{m} \mathrm{sec}^{-1}\right)$

$\alpha \quad$ Parameter defined in Eq. [6] (-)

$\beta \quad$ Contact angle between the dispersion medium and the pore wall of the support (degrees)

$\gamma \quad$ Surface tension of the liquid in the support $\left(\mathrm{N} \mathrm{m}^{-1}\right)$

$\eta \quad$ Viscosity of the liquid flowing through the gel layer and the support $\left(\mathrm{N} \mathrm{m}^{-2}\right.$ sec)

$\theta_{\mathrm{g}} \quad$ Volume fraction pores of the wet gel layer (-)

$\theta_{s} \quad$ Volume fraction pores of the support $(-)$

\section{ACKNOWLEDGMENTS}

We would like to thank Prof. Dr. C. A. Smolders and Dr. D. Bargeman for the stimulating discussions, Mr. G. B. J. Borggreve and Mr. D. Wesseling for their technical assistance, and Dr. Ir. J. de Lau and Ir. C. A. M. van den Broek of the ceramic laboratories of Philips N. V. (Elcoma) for supplying the type 1 support. The financial assistance from the Ministries of Science Affairs and Economical affairs is gratefully appreciated.

\section{REFERENCES}

1. Leenaars, A. F. M., Keizer, K., and Burggraaf, A. J., J. Mater. Sci., in press.

2. Leenaars, A. F. M., Keizer, K., and Burggraaf, A. J., "Separation with Inorganic Membranes." Laboratory for Inorganic Chemistry and Materials Science, Twente University of Technology, Enschede, December 1982. [in Dutch]

3. Keizer, K., Leenaars, A. F. M., and Burggraaf, A. J., in "European Colloquium on Ceramics in Advanced Energy Technologies, 20-22 September 1982, Petten, The Netherlands," in press.

4. Wilson, S. J., and Stacey, M. H., J. Colloid Interface Sci. 82, 507 (1981).

5. Hermans, P. H., and Bredée, H. L., Rec. Trav. Chim. 54, 680 (1935).

6. Freilich, D., and Tanny, G. B., J. Colloid Interface Sci. 64, 362 (1978).

7. Kerker, M., "The Scattering of Light and Other Electromagnetic Radiation," Chap. 7. Academic Press, New York, 1969. 
8. Ramsay, J. D. F., Daish, S. R., and Wright, C. J., Faraday Disc. Chem. Soc. 65, 66 (1978).

9. Kingery, W. D., "Introduction to Ceramics," p. 51 . Wiley, New York, 1960.

10. Grimshaw, R. W., "The Chemistry and Physics of Clays," 4th ed., p. 520. E. Benn, London, 1971.

11. Adcock, D. S., and McDowall, I. C., J. Amer. Ceram. Soc. 40, 355 (1957).

12. Dal, P. H., and Berden, W. J. H., in "Proceedings of the 4th International Conference on Science of Ceramics" (G. H. Stewart, Ed.), p. 113. Brit. Ceramic Soc., 1968.

13. Fenelly, T. J., and Reed, J. S., J. Amer. Ceram. Soc. 55, 264 (1972).

14. "Handbook of Chemistry and Physics" (R. C. Weast,
Ed.), 55th ed., p. F43, F49. Chemical Rubber Co., 1974.

15. Carman, P. C., Trans. Inst. Chem. Eng. 15, 150 (1937).

16. Levine, S., Marriott, J. R., Neale, G., and Epstein, N., J. Colloid Interface Sci. 52, 136 (1975).

17. Broz, Z., and Epstein, N., J. Colloid Interface Sci. 56, 605 (1976).

18. Anderson, J. L., and Koh, W. H., J. Colloid Interface Sci. 59, 149 (1977).

19. Belfort, G., Scherfig, J., and Seevers, D. O., $J$. Colloid Interface Sci. 47, 106 (1974).

20. Belfort, G., and Scherfig, J., Desalination 18, 59 (1976).

21. Yoldas, B. E., J. Mater. Sci. 10, 1856 (1975). 